\title{
The Role of Alvarado and Pediatric Appendicitis Score in Acute Appendicitis in Children
}

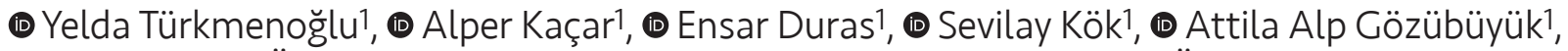

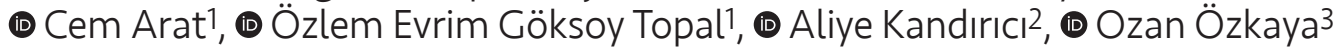 \\ 1University of Health Science, Okmeydanı Training and Research Hospital, Clinic of Pediatrics, İstanbul, Turkey \\ 2University of Health Science, Okmeydanı Training and Research Hospital, Clinic of Pediatric Surgeon, İstanbul, Turkey \\ 3istinye University Faculty of Medicine, Department of Pediatrics, İstanbul, Turkey
}

\begin{abstract}
Aim: Acute appendicitis (AA) is the condition that most commonly requires a surgical procedure in children presenting to the emergency department with acute abdominal pain. Alvarado and Pediatric Appendicitis scores (PAS) are the most widely used scoring systems in the diagnosis of AA in children. This study aims to evaluate the effectiveness of Alvarado and PAS scores in the diagnosis of AA in children.

Materials and Methods: One hundred and two patients aged 3-17 years, who were admitted to the pediatric emergency department with acute abdominal pain and had a clinical suspicion of AA were included in this retrospective study. The demographic characteristics, laboratory and radiological findings, and Alvarado and PAS scores were obtained from the records of the patients, retrospectively. According to the results of pathology, $n=48$ patients for the AA group and $n=54$ patients for the non-AA group were identified. The AA and non-AA groups were compared in terms of PAS and Alvarado scores.

Results: The mean age of the 102 patients was $9.38 \pm 3.90$ years, and $62(60.85 \%)$ of them were male. The median PAS score was $7.79 \pm 1.2$ and $5.52 \pm 1.34$, and the median Alvarado score was $7.98 \pm 1.14$ and $5.89 \pm 1.53$ in the AA and $\mathrm{N}-\mathrm{AA}$ groups, respectively $(\mathrm{p}<0.001 ; \mathrm{p}<0.001)$. For the PAS, the cut-off score was $>7$ with a sensitivity of $66.7 \%$, a specificity of $94.4 \%$, a positive predictive value (PPV) of $91.4 \%$, and a negative predictive value (NPV) of $76.1 \%$ ( $p<0.001)$. For the Alvarado score, the cut-off was also $>7$, with a sensitivity of $77.1 \%$, a specificity of $85.2 \%$, PPV of $82.2 \%$, and NPV of $80.7 \%(p<0.001)$.
\end{abstract}

Conclusion: Although both PAS and Alvarado scores provide useful diagnostic information in patients suspected of AA, neither of them is enough to diagnose AA alone.

Keywords: Appendicitis, Alvarado score, children, PAS

\section{Introduction}

Acute appendicitis (AA) is the condition that most commonly requires a surgical procedure in children presenting to the emergency department with a sudden onset of abdominal pain (1).

Although the incidence is not known precisely, it is on the scale of $5.9 / 10,000$ in the $0-9$ years old age range, and
$15.3 / 10,000$ in the 10-19 years old age range in the United States of America (2). Also, in acute abdominal pain in children, AA was diagnosed for $7.4 \%$ in Australia (3). It has been shown that children with acute abdominal pain initially received other diagnoses frequently seen in children such as acute gastroenteritis, pneumonia, urinary tract infection, or mesenteric lymphadenitis (4). Perforation and related 
complications can be seen if the diagnosis cannot be made in time (4-7). In contrast to this, the frequency of negative appendectomy is reported to be at rates of $3.7-17 \%(7,8)$. Abdominal ultrasound (USG) is the most commonly used radiological method to help in making a correct diagnosis. Its sensitivity varies from $66.2 \%$ to $85 \%$ according to the practitioner's experience (8-10). The sensitivity of abdominal computed tomography (CT) is reported to be $95-97 \%$, but there are risks such as radiation and post-contrast reactions $(11,12)$. Therefore, scoring systems based on symptoms, physical examination, and laboratory findings have begun to be used. The Alvarado score, which was initially applied in adults, is also used in children. Subsequently, the Pediatric Appendicitis score (PAS) was developed by Samuel (13) in 2002. The Alvarado score and PAS have been reported to reduce the use of $C T$ in the diagnosis of $A A$ for patients between 3 and 16 years of age $(14,15)$. This study aims to determine the PAS and Alvarado scores in patients admitted to the pediatric emergency department and considered to have $A A$, and to compare them in terms of applicability, safety, and specificity in the diagnosis of AA.

\section{Materials and Methods}

The retrospective observational study was conducted between November 2014 and November 2015, in the Clinic of Pediatric Emergency of Okmeydani Training and Research Hospital. The study included children aged 3-17 years who were admitted to the pediatric emergency department. Those patients who had a pain duration of less than 96 hours and were considered to have AA (abdominal sensitivity and defense or rebound tenderness positivity) after an examination by a pediatrician were included in this study. Pregnant patients, patients with chronic inflammatory bowel disease, cystic fibrosis, or sickle cell anemia, patients who had undergone a previous abdominal operation or abdominal tomography within the last two weeks and those who had received corticosteroids for more than two weeks, and immunosuppressed patients were not included in this study. The information cards of each patient were filled out before surgical consultation. Consent forms were obtained from the parents or the children. The age, gender, duration of pain, complaint (complaints of abdominal pain and duration, fever, nausea-vomiting, diarrhea, upper respiratory tract infection) physical examination findings (right lower quadrant sensitivity, defense, rebound tenderness, percussion/cough/right lower quadrant sensitivity with jumping) leucocyte count and neutrophil percentages, biochemistry, C-reactive protein, complete urine test, and PAS and Alvarado score parameters were marked on the forms of these patients.

According to previous studies, a neutrophil count $\geq 75 \%$ and a body temperature over $38{ }^{\circ} \mathrm{C}$ were accepted as fever. The parameters of PAS and Alvarado scores and their scoring systems are shown in Table I (16-18). All the patients underwent USG, and USC was considered to be positive in the presence of signs such as a fixed appendix, no compression, round transverse image appendix, thickening in the intestine wall, appendix inner diameter $>6 \mathrm{~mm}$, decreased mobility, irregular appearance in appendix, and peri-appendicular fluid appearance $(9,10)$. All other USC findings were accepted as negative. A pediatric surgeon consulted with all the patients. The pediatric surgeon and the radiologist were not informed about the PAS and Alvarado scores. Other laboratory data and the radiological and pathological results of the patients were obtained from the system records. Those patients who were discharged

Table I. Alvarado and pediatric appendicitis scoring system (16-18)

\begin{tabular}{|c|c|c|c|}
\hline \multicolumn{2}{|l|}{ Alvarado score } & \multicolumn{2}{|l|}{ Pediatric Appendicitis score } \\
\hline Feature & Point value & Feature & Point value \\
\hline Migration of pain & 1 & Migration of pain & 1 \\
\hline Anorexia & 1 & Anorexia & 1 \\
\hline Nausea/vomiting & 1 & Nausea/vomiting & 1 \\
\hline Signs RLQ tenderness & 2 & Signs RLQ tenderness & 2 \\
\hline Rebound pain & 1 & Cough/hopping/percussion tenderness in the RLQ & 2 \\
\hline Elevation of temperature $\left(38^{\circ} \mathrm{C}\right)$ & 1 & Elevation of temperature $\left(38^{\circ} \mathrm{C}\right)$ & 1 \\
\hline Leukocytosis $\geq 10^{9} / \mathrm{L}$ & 2 & Leukocytosis $\geq 10^{9} / \mathrm{L}$ & 1 \\
\hline Polymorphonuclear neutrophilia $\geq 75 \%$ & 1 & Polymorphonuclear neutrophilia $\geq 75 \%$ & 1 \\
\hline Total & 10 & Total & 10 \\
\hline
\end{tabular}


without being operated on were called up and asked about whether they had undergone an operation within the previous two weeks. AA was diagnosed according to the observation of the pediatric surgeon during the operation and the pathology reports. Those patients who underwent surgery and were diagnosed with AA pathologically were accepted as the AA group, and those who did not undergo surgery or who underwent surgery but pathology results did not confirm AA were accepted as the non-AA group. The demographical characteristics, clinical, radiological and laboratory results, cut-off values of PAS and Alvarado scores, sensitivity and specificity values, positive predictive values (PPV), and negative predictive values (NPV) of the $A A$ and non-AA groups were compared. Permission from the local ethics committee for this study was received from Okmeydani Training and Research Hospital Ethics Commitee (09/02/2016-416).

\section{Statistical Analysis}

The SPSS 22.0 (IBM SPSS, Turkey) was used in the analysis of the variables in this study. The conformity of the parameters to normal distribution was evaluated by Shapiro-Wilks test. In the comparison of quantitative data, Student's t-test was used for two groups of parameters with normal distribution and Mann-Whitney $U$ test was used for two groups of parameters without normal distribution. In the comparison of qualitative data, chi-square test and Continuity (Yates) Correction was used. In the cutoff point identification, receiver operating characteristic (ROC) analysis was used, in the sensitivity and specificity calculations, diagnostic screening tests were used. The significance level was accepted as $p<0.05$. To compare qualitative parameters, Pearson chi-square test was used. For detecting cut-off points, ROC analysis was used, and for calculating sensitivity and specificity, diagnostic and screening tests were used. The DeLong method was used to compare two areas under the receiver operating characteristics curve (AUROC). The significance level was accepted as $\mathrm{p}<0.05$.

\section{Results}

Of the 121 patients who were included in the study with the consideration of $A A, 12$ were excluded from the study due to a lack of information in the records and 5 because they could not be reached by phone. Of the remaining patients, 53 underwent surgery and one was diagnosed with Meckel's diverticulum and one with ovarian cyst; these 2 patients were excluded from the study. The mean age of the final 102 patients was $9.38 \pm 3.90$ years (3-15.5 years), and 62 (60.8\%) of them were male. Based on the pathological diagnoses, one patient had lymphoid hyperplasia, one patient had normal tissue, and one patient had carcinoid tumor. These 3 patients were excluded from the AA group and included in the non-AA group. The number of patients was 48 (47.1\%) in the AA group and 54 (52.9\%) in the non-AA group. There was no statistically significant difference between the two groups in terms of age, gender, and admission times. The most common finding (97.9\%) of those patients in the AA group was sensitivity in the right lower quadrant. While there was a statistically significant difference between the AA group and the non-AA group in terms of sensitivity in the right lower quadrant, pain in the right lower quadrant with cough/percussion/hopping, migration of pain to the right lower quadrant, rebound tenderness, leukocytosis, or shift to the left, there was no statistically significant difference between the two groups in terms of anorexia, nausea-vomiting, or fever (Table II).

Among the patients in the AA group, the minimum PAS and Alvarado score was 5, the maximum score was 10 and all of patients who had scores of either 9 or 10 were in the AA group, while in the non-AA group, the minimum PAS and Alvarado score was 3, and the maximum score was 8 .

For the PAS score, the cut-off value was $>7,[95 \%$ confidence interval $(\mathrm{Cl})$, area under curve $(\mathrm{AUC})=0.88 \pm 0.3]$ sensitivity was $66.7 \%$, specificity was $94.4 \%$, PPV was $91.4 \%$, and the NPV was $76.1 \%(p<0.001)$ (Figure 1). For the Alvarado score, the cut-off value was $>7,(95 \% \mathrm{Cl}$, AUC was $0.87 \pm 0.03)$, sensitivity was $77.1 \%$, specificity was $85.2 \%$, PPV was $82.2 \%$, and NPV was $80.7 \%(p<0.001)$ (Figure 1). By using the DeLong method, no statistically

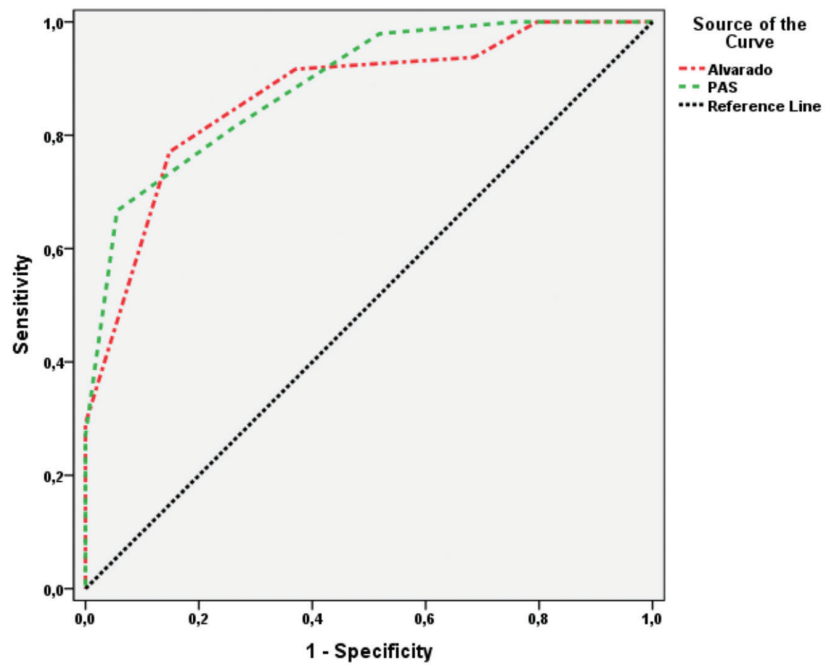

Figure 1. ROC curve of PAS and Alvarado score of patients ROC: Receiver operating characteristic, PAS: Pediatric Appendicitis score 
significant difference was found between the AUROC levels for Alvarado and PAS variables $(p=0.530)$.

The USG findings were positive in 34 (70.8\%) patients in the AA group, and 5 (9.3\%) patients in the non-AA group. There was a significant difference in USC findings between the two groups $(p<0.001)$ (Table II). For those patients in the AA group, PAS and Alvarado scores were in the intermediate or high risk group. There was statistically significant difference only for patients with Alvarado intermediate score in the comparison of USC results with the PAS and Alvarado scores of intermediate and high-risk group in patients in the AA group ( $p=0.047$ ) (Table III). Abdominal $\mathrm{CT}$ was performed in 4 patients, and the results showed appendicitis in 2 of them, and the other patients underwent an operation after being evaluated by a surgeon.

Of the 51 patients who underwent surgery, negative appendectomy was seen in $3(5.9 \%)$ patients. Of these patients, one had carcinoid tumor, one had lymphadenopathy and one had normal tissue (7-5); and the PAS and Alvarado scores of these patients were 8-8, 7-8, 7-5, respectively. Considering the pathological diagnoses of those patients

Table III. The comparison of ultrasound findings with the scores in acute appendicitis patients

\begin{tabular}{|c|c|c|c|}
\hline & USG (-) & USG (+) & \multirow[t]{2}{*}{$p$} \\
\hline & n (\%) & n (\%) & \\
\hline \multicolumn{4}{|c|}{ Alvarado } \\
\hline $5+6$ & 20 (37.7) & $7(18.4)$ & \multirow[t]{2}{*}{$0.047^{*}$} \\
\hline$\geq 7$ & $33(62.3)$ & $31(81.6)$ & \\
\hline \multicolumn{4}{|l|}{ PAS } \\
\hline $5+6$ & $25(49.0)$ & $11(28.9)$ & 0.056 \\
\hline$\geq 7$ & $26(51.0)$ & $27(71.1)$ & \\
\hline
\end{tabular}

Table II. Features of group acute appendicitis and group non-acute appendicitis

\begin{tabular}{|c|c|c|c|c|}
\hline & AA $(n=48)$ & Non-AA $(n=54)$ & Total $(n=102)$ & \multirow[t]{2}{*}{$\mathbf{p}$} \\
\hline & Med \pm SD & Med \pm SD & Med \pm SD & \\
\hline Age & $10.09 \pm 3.79$ & $8.75 \pm 3.91$ & $9.38 \pm 3.90$ & ${ }^{1} 0.082$ \\
\hline Duration (hour) $)_{\text {(med) }}$ & $33.98 \pm 25.17(24)$ & $35.31 \pm 22.78(24)$ & $34.69 \pm 23.82(24)$ & ${ }^{2} 0.386$ \\
\hline Alvarado score $_{(\text {med) }}$ & $7.98 \pm 1.14(8)$ & $5.89 \pm 1.53(6)$ & $6.87 \pm 1.71(7)$ & ${ }^{2}<0.001^{*}$ \\
\hline $\mathrm{PAS}_{\text {(med) }}$ & $7.79 \pm 1.2(8)$ & $5.52 \pm 1.34(6)$ & $6.59 \pm 1.71(7)$ & ${ }^{2}<0.001^{*}$ \\
\hline C-reactive protein $_{(\mathrm{med})(\mathrm{mg} / \mathrm{L})}$ & $54.51 \pm 76.98(18.58)$ & $31.12 \pm 62.52(12.3)$ & $42.13 \pm 70.33(14.4)$ & ${ }^{20} 0.038^{*}$ \\
\hline Leukocytes count t $\left(10^{9} / L\right)$ & $16804.79 \pm 4822.02$ & $14211.11 \pm 6825.95$ & $15431.67 \pm 6079.71$ & ${ }^{1} 0.031^{*}$ \\
\hline \multirow[t]{2}{*}{ Polymorphonuclear neutrophilia a $\left(10^{9} / \mathrm{L}\right)$} & $12603.37 \pm 4220.14$ & $10000.74 \pm 5802.04$ & $11225.51 \pm 5258.99$ & ${ }^{1} 0.012^{*}$ \\
\hline & $\mathrm{n}(\%)$ & $\mathrm{n}(\%)$ & $\mathrm{n}(\%)$ & \\
\hline \multicolumn{5}{|l|}{ Gender } \\
\hline Female & $17(35.4)$ & $23(42.6)$ & $40(39.2)$ & \multirow[t]{2}{*}{${ }^{3} 0.459$} \\
\hline Male & $31(64.6)$ & $31(57.4)$ & $62(60.8)$ & \\
\hline Signs RLQ tenderness & $47(97.9)$ & $42(77.8)$ & $89(87.3)$ & ${ }^{3} 0.002^{*}$ \\
\hline Migration of pain & $32(66.7)$ & $8(14.8)$ & $40(39.2)$ & ${ }^{3}<0.001^{*}$ \\
\hline $\begin{array}{l}\text { Cough/hopping/percussion } \\
\text { tenderness in the RLQ }\end{array}$ & $36(75)$ & $18(33.3)$ & $54(52.9)$ & ${ }^{3}<0.001^{*}$ \\
\hline Rebound pain & $35(72.9)$ & $13(24.1)$ & $48(47.1)$ & ${ }^{3}<0.001^{*}$ \\
\hline Elevation of temperature & $11(22.9)$ & $20(37)$ & $31(30.4)$ & ${ }^{3} 0.122$ \\
\hline Anorexia & $38(79.2)$ & $42(77.8)$ & $80(78.4)$ & ${ }^{3} 0.865$ \\
\hline Nausea/vomiting & $36(75)$ & $35(64.8)$ & $71(69.6)$ & ${ }^{3} 0.264$ \\
\hline Leukocytosis $\geq 1010^{9} / \mathrm{L}$ & $46(95.8)$ & $40(74.1)$ & $86(84.3)$ & ${ }^{3} 0.003^{*}$ \\
\hline Polymorphonuclear neutrophilia $\geq 75 \%$ & 44 (91.7) & $36(66.7)$ & $80(78.4)$ & ${ }^{3} 0.002^{*}$ \\
\hline USG & $34(70.8)$ & $5(9.3)$ & $39(38.2)$ & ${ }^{3}<0.001^{*}$ \\
\hline
\end{tabular}


in the AA group, 31 (64.6\%) patients were diagnosed with phlegmonous appendicitis, 9 (18.7\%) with gangrenous appendicitis, and 8 (16.7\%) with perforated appendicitis. Of the patients in the non-AA group, 18 (35.3\%) were diagnosed as acute gastroenteritis, 15 (29.4\%) with constipation, 13 (25.5\%) with mesenteric lymphadenomegaly, 2 (3.9\%) with urinary tract infections, 1 (1.9\%) with dysmenorrhea, 1 (1.9\%) with Henoch-Schönlein purpura, and 1 (1.9\%) with nephrolithiasis.

\section{Discussion}

Sensitivity in the right lower quadrant is the most common finding in appendicitis and is reported at a frequency of $78-100 \%$ in different series $(1,15)$. Among other symptoms compatible with appendicitis, the shift of pain to the right lower quadrant is seen at a frequency of 33-69\%, rebound pain at a frequency of $15-68 \%$, and pain in the right lower quadrant with cough/percussion/jumping at a frequency of $64-83.2 \%(15,18-21)$. Leukocytosis frequency is $83-93 \%$ and an increase of the neutrophil ratio frequency is seen in $75-96 \%$ of cases with appendicitis (18-21). In our study, these ratios were found to be significantly higher than those of the non-AA group ( $p=0.003 ; p=0.02)$.

Samuel (13) determined the cut-off value to be 6 for the PAS. The cut-off value has been reported to be between 7-10, sensitivity to be between $61-86 \%$, and specificity to be between $50-96 \%$ for the PAS in the different studies $(15,19$ 22). The PPV values were between $50.7 \%$ and $90.1 \%$, and NPV values were between $38 \%$ and $87.9 \%(15,19,20,23,24)$. Similarly, the cut-off value was $>7$, sensitivity was $66.7 \%$, specificity was $94.4 \%$, PPV was $91.4 \%$, and NPV was $76.1 \%$ in our study. The cut-off values for the Alvarado score were similar to PAS. While the cut-off value was 7, the sensitivity was $68.5 \%$ to $89 \%$, specificity was $59 \%$ to $81 \%$, PPV was $54.9 \%$ to $93.1 \%$ and NPV was $46 \%$ to $85.3 \%(15,18-20,23,24)$. Similarly, in our study, the cut-off value was $>7$, while the sensitivity was $77.1 \%$, specificity was $85.2 \%$, PPV was $82.2 \%$, and NPV was $80.7 \%$ for the Alvarado score. In our study, all of the patients had intermediate or high-risk scores for both PAS and Alvarado scores. On the other hand, when analyzed with ROC, there was no statistically significant difference in sensitivity, specificity, PPV and NPV between the PAS and Alvarado scores.

In the diagnosis of AA, the sensitivity of abdominal USG varies according to the experience of the practitioner, the visualization of the appendix, the gender of the patient, the patient's body weight, and the visualization of the perforated appendicitis. The abdominal USG sensitivity for AA diagnosis varies between $53 \%$ and $88.2 \%$ and specificity between $84 \%$ and $93 \%$ in different series $(10,16,23,25-28)$. On the other hand, the false positive USC frequency is seen to be between $5 \%$ and $30 \%(23,29-31)$. It has been suggested that the USC positivity and diagnosis rate increases as the duration of pain increases in these patients (27). Although Alvarado and PAS recommends radiological methods, especially USC, for those patients with intermediate scores, some other centers also recommend using radiological methods for those patients with lower scores $(28,29)$. In our study, abdominal USG was found to be positive in $70.8 \%$ of those patients in the AA group, and in $9.3 \%$ of those patients in the N-AA group. Sincavage et al. (25) showed intermediate risk AS (4-6), US was positive for appendicitis in $21 \%$. Our study had similar results.

Perforation can be a fatal complication in AA in children. Perforation frequency between $7.5 \%$ and $30 \%$ has been reported in various studies $(16,29,32,33)$. According to the results of the pathologic examinations, the simple or phlegmonous appendicitis is reported at a frequency of $25 \%$ to $57.1 \%$, gangrenous or suppurative appendicitis at a frequency of $34 \%$ to $45 \%$, and perforated appendicitis at a frequency of $12 \%$ to $21 \%(4,32,33)$. In our study, 31 (64.6\%) patients were diagnosed with simple appendicitis, $9(18.7 \%)$ patients with gangrenous appendicitis, and 8 (16.7\%) patients with perforated appendicitis.

In children, negative appendectomy rates are reported between $3.7 \%$ and $13 \%$ in different series $(7,8,16,32,33)$. While it is expected that the rate of negative appendectomy in high-score patients is low, Zúñiga et al. (33) found negative appendectomy to be at a rate of $4.95 \%$ in those with a PAS score above eight. In our study, all patients with a score of more than 8 were in the AA group. The pathologic diagnoses were normal tissue, fecaliths, lymphoid hyperplasia, pinworm, granuloma, Meckel's diverticulum, granuloma, fibrose obliteration, and carcinoid tumor $(34,35)$. Three $(5.9 \%)$ patients had a negative appendectomy. The scores of these 3 patients were between 5 and 8 and they were diagnosed as normal tissue, lymphoid hyperplasia and carcinoid tumor pathologically. The patient who was pathologically diagnosed with carcinoid tumor had an Alvarado score of 8, a PAS score of 8, leukocytosis, and shift to the left, but no USG findings. If positive USG findings, leukocytosis and neutrophyl count $>75 \%$ are not observed together in a patient, close follow-up and radiologic re-evaluation should be considered.

\section{Study Limitations}

Firstly, this study was conducted with a limited number of patients. Secondly, the patients were not all examined 
by the same physician. Finally, the fact that the patients did not apply within the same period following the onset of the complaint is thought to affect the clinical staging, laboratory findings, and radiological findings.

\section{Conclusion}

AA is a condition that is still hard to diagnose in children presenting with acute abdominal pain in the emergency department. Although both Alvarado and PAS scores provide useful information in patients suspected of having AA in the pediatric emergency department, neither of them is enough to diagnose AA alone. The possibility of AA is high in children with a PAS and Alvarado score of 5 or more in the presence of radiological findings. There is a need for new parameters in the scoring system.

\section{Ethics}

Ethics Committee Approval: Permission from the local ethics committee for this study was received from Okmeydani Training and Research Hospital Ethics Commitee (09/02/2016-416).

Informed Consent: Consent forms were obtained from the parents or the children.

Peer-review: Externally peer-reviewed.

\section{Authorship Contributions}

Concept: Y.T., A.K., E.D., S.K., A.A.G., C.A., Ö.E.G.T., A.Kan., O.Ö., Design: Y.T., A.K., E.D., S.K., A.A.G., C.A., Ö.E.G.T., A.Kan., O.Ö., Data Collection or Processing: A.K., S.K., A.A.G., Ö.E.G.T., A.Kan., Analysis or Interpretation: A.K., Y.T., C.A., A.Kan., O.Ö., Literature Search: S.K., Ö.E.G.T., Writing: Y.T., E.D.

Conflict of Interest: None of the authors had conflict of interest.

Financial Disclosure: The authors declared that this study received no financial support.

\section{References}

1. Benabbas R, Hanna M, Shah I, Sinert R. Diagnostic accuracy of history, physical examination, laboratory tests, and pointof-care Ultrasound for Pediatric Acute Appendicitis in the Emergency Department: A systematic review and metaanalysis. Acad Emerg Med 2017; 24:523-51.

2. Buckius MT, McGrath B, Monk J, Grim R, Bell T, Ahuja V. Changing epidemiology of acute appendicitis in the United States: study period 1993-2008. I Surg Res 2012; 175:185-90.

3. Lee $W H, O$ 'Brien $S$, Skarin $D$, et al. Pediatric Abdominal Pain in Children Presenting to the Emergency Department. Pediatr Emerg Care 2019.

4. Galai T, Beloosesky OZ, Scolnik D, Rimon A, Glatstein M. Misdiagnosis of Acute Appendicitis in children attending the
Emergency Department: The experience of a large, Tertiary Care Pediatric Hospital. Eur J Pediatr Surg 2017; 27:138-141.

5. Sung T, Callahan MJ, Taylor GA. Clinical and imaging mimickers of acute appendicitis in the pediatric population. AJR Am I Roentgenol 2006; 186:67-74.

6. Kosloske AM, Love CL, Rohrer JE, Goldthorn JF, Lacey SR. The diagnosis of appendicitis in children: outcomes of a strategy based on pediatric surgical evaluation. Pediatrics 2004; 113(1pt1):29-34.

7. Applegate KE, Sivit C), Salvator AE, et al. Effect of crosssectional imaging on negative appendectomy and perforation rates in children. Radiology 2001; 220:103-7.

8. Kaiser $\mathrm{S}$, Jorulf H, Söderman E, Frenckner B. Impact of radiologic imaging on the surgical decision-making process in suspected appendicitis in children. Acad Radiol 2004; 11:971-9.

9. Löfvenberg F, Salö M. Ultrasound for Appendicitis: Performance and integration with clinical parameters. Biomed Res Int 2016; 6:5697692.

10. Sivitz AB, Cohen SG, Tejani C. Evaluation of acute appendicitis by pediatric emergency physician sonography. Ann Emerg Med 2014; 64:358-64.e4.

11. Rezak A, Abbas HM, Ajemian MS, Dudrick SJ, Kwasnik EM Decreased use of computed tomography with a modified clinical scoring system in diagnosis of pediatric acute appendicitis. Arch Surg 2011; 146:64-7.

12. Sivit C), Applegate KE, Stallion A, et al. Evaluation of suspected appendicitis in children and young adults: helical CT. Radiology 2000; 216:430-3.

13. Samuel M. Pediatric appendicitis score. / Pediatr Surg 2002; 37:877-81

14. Russell WS, Schuh AM, Hill JG, et al. Clinical practice guidelines for pediatric appendicitis evaluation can decrease computed tomography utilization while maintaining diagnostic accuracy. Pediatr Emerg Care 2013; 29:568-73.

15. Kim DY, Shim DH, Cho KY. Use of the Pediatric Appendicitis Score in a Community Hospital. Indian Pediatr 2016; 53:217-20.

16. Schneider C, Kharbanda A, Bachur R. Evaluating appendicitis scoring systems using a prospective pediatric cohort. Ann Emerg Med 2007; 49:778-84.

17. Goldman RD, Carter S, Stephens D, Antoon R, Mounstephen W, Langer JC. Prospective validation of the pediatric appendicitis score. J Pediatr 2008: 153:278-82.

18. Bhatt M, Joseph L, Ducharme FM, Dougherty G, McGillivray D. Prospective validation of the pediatric appendicitis score in a Canadian pediatric emergency department. Acad Emerg Med 2009; 16:591-6.

19. Khanafer I, Martin DA, Mitra TP, et al. Test characteristics of common appendicitis scores with and without laboratory investigations: a prospective observational study. BMC Pediatr 2016; 6:147.

20. Cayrol I, Miguez MC, Guerrero G, Tomatis C, Simal I, Marañón R. Diagnostic accuracy and prognostic utility of D Dimer in acute appendicitis in children. Eur J Pediatr 2016; 175:313-20.

21. Saucier A, Huang EY, Emeremni CA, Pershad I. Prospective evaluation for a clinical pathway for suspected appendicitis. Pediatrics 2014; 133:e88-95. 
22. Bal A, Anil M, Nartürk $M$, et al. Importance of Clinical Decision Making by Experienced Pediatric Surgeons When Children Are Suspected of having Acute Appendicitis. Pediatr Emerg Care 2017; 33:e38-42.

23. Macklin CP, Radcliffe GS, Merei JM, Stringer MD. A prospective evaluation of the modified Alvarado score for acute appendicitis in children. Ann R Coll Surg Engl 1997; 79:203-5.

24. Escribá A, Gamell AM, Fernández Y, Quintillá JM, Cubells $C L$. Prospective validation of two systems of classification for the diagnosis of acute appendicitis. Pediatr Emerg Care 2011; 27:1659.

25. Sincavage J, Buonpane C, Benyamen B, et. al. Alvarado Scores Predict Additive Value of Magnetic Resonance Imaging in Workup of Suspected Appendicitis in Children. I Surg Res 2019. 244:42-9.

26. Aydin D, Turan C, Yurtseven A, et al. Integration of radiology and clinical score in pediatric appendicitis. Pediatr Int 2018; 60:173-8.

27. Bachur RG, Dayan PS, Bajaj L, et al. The effect of abdominal pain duration on the accuracy of diagnostic imaging for pediatric appendicitis. Ann Emerg Med 2012; 60:582-90.

28. Blitman NM, Anwar M, Brady KB, Taragin BH, Freeman K. Value of focused appendicitis ultrasound and Alvarado score in predicting appendicitis in children: Can we reduce the use of CT? AJR Am J Roentgenol 2015; 204:707-12.
29. Mandeville $K$, Pottker T, Bulloch B, Liu J. Using appendicitis scores in the pediatric ED. Am J Emerg Med 2011; 29:972-7.

30. Athans BS, Depinet HE, Towbin AJ, Zhang Y, Zhang B, Trout AT Use of Clinical Data to Predict Appendicitis in Patients with Equivocal US Findings. Radiology 2016; 280:557-67.

31. Toprak $\mathrm{H}$, Kilincaslan $\mathrm{H}$, Ahmad IC, et al. Integration of ultrasound findings with Alvarado score in children with suspected appendicitis. Pediatr Int 2014; 56:95-9.

32. Mariadason JG, Wang WN, Wallack MK, Belmonte A, Matari $\mathrm{H}$. Negative appendicectomy rate as a quality metric in the management of appendicitis: impact of computed tomography, Alvarado score and the definition of negative appendicectomy. Ann R Coll Surg Engl 2012; 94:395-401.

33. Zúñiga RV, Arribas IL, Montes SP, et al. Application of Pediatric Appendicitis Score on the emergency department of a secondary level hospital. Pediatr Emerg Care 2012; 28:489-92.

34. Maloney C, Edelman MC, Bolognese AC, Lipskar AM, Rich BS. The Impact of Pathological Criteria on Pediatric Negative Appendectomy Rate. I Pediatr Surg 2019; 54:1794-9.

35. Amr B, Froghi F, Edmond M, Haq K, Thengungal Kochupapy R. Management and outcomes of appendicular neuroendocrine tumours: Retrospective review with 5-year follow-up. Eur / Surg Oncol 2015; 41:1243-6. 